\title{
Research on Safety System of High Altitude Live Working Vehicle
}

\author{
Yinbo Du, Li Tan, Lei Xia \& Hong Xiang \\ State Grid Chongqing Electric Power CO. Electric Power Research Institute, Chongqing 404100, China \\ Dahong Wang \\ Shenzhen Institute of Advanced Smart Technology, Shenzhen 518055, China
}

\begin{abstract}
In order to fully protect the safety of live working personnel, high electric vehicle must implement multiple safety protection. First is the safety of the hydraulic system, not in office under the condition of artificial active operation can realize self-locking; Then the insulation safety, in can't breakdown voltage 10 $\mathrm{kv}$, ensuring the security of the charged homework; Finally take tram pose security itself, take tram must bring Angle sensor and torque sensor. The three important protect build a work charged car security system, comprehensive security charged the personal safety of workers.
\end{abstract}

KEYWORD: hydraulic system; self-locking; insulation safety

\section{INTRODUCTION}

Aerial electric operation vehicle usually refers to charged high-altitude operations in more than $10 \mathrm{kV}$ line, the working bucket, arm, control circuit and line, bucket arm combination can meet the insulation performance indicators, and with earth wire. Aerial work vehicle is developed on the basis of aerial work vehicle, and it is a kind of special vehicle which has the potential operation on the occasions of convenient traffic and complicated wiring. A collection of automotive chassis, hydraulic systems, electrical control, insulation technology and communication alarm and other disciplines. The operating frequency is not high, the load is small, but the requirements of reliability, high security, and flexible operation, rapid response.

\section{SECURITY SYSTEM DESIGN}

\subsection{Hydraulic self locking system}

Hydraulic self locking system is divided into the oil circuit and mechanical type. Oil circuit self locking is the installation of double control one-way valve for holding pressure, so that the oil cylinder hydraulic oil does not return to the fuel tank, oil tank filled with a certain pressure oil. The pressure retaining locking is achieved under the premise of the hydraulic pipeline is reliable, if the pipes are leaking plung- er or slowly back to the place. High altitude car line working car support leg pressure using a one-way valve and pressure regulating valve in parallel, as shown in figure 2-1. To ensure the stability of the hydraulic cylinder (Zhang Hua et al, 2009).

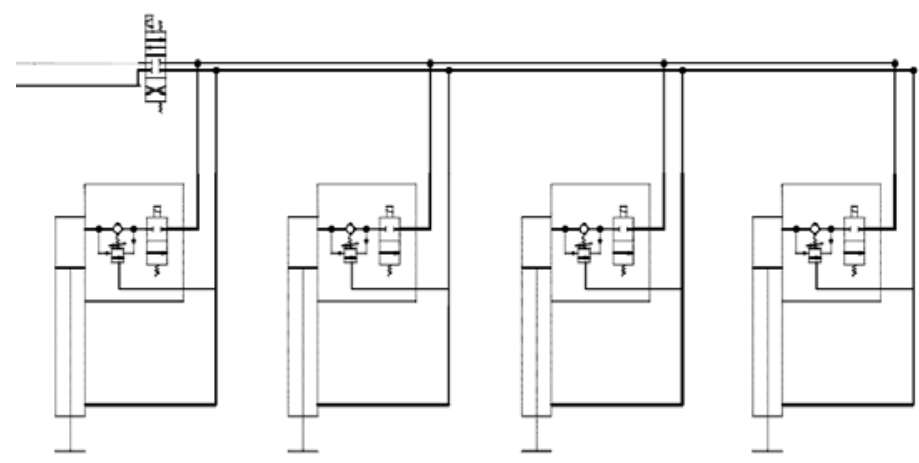

Figure 2-1. Supporting legs hydraulic schematic

Two oil cylinders are controlled by an electromagnetic valve, and each hydraulic cylinder is provided with a one-way valve and a pressure regulating valve in parallel, and the pressure feedback module is provided with a pressure stabilizing oil pump and a pressure feedback module. Multiple security measures to ensure the stability of the folding arm support, as shown in figure 2-2. 


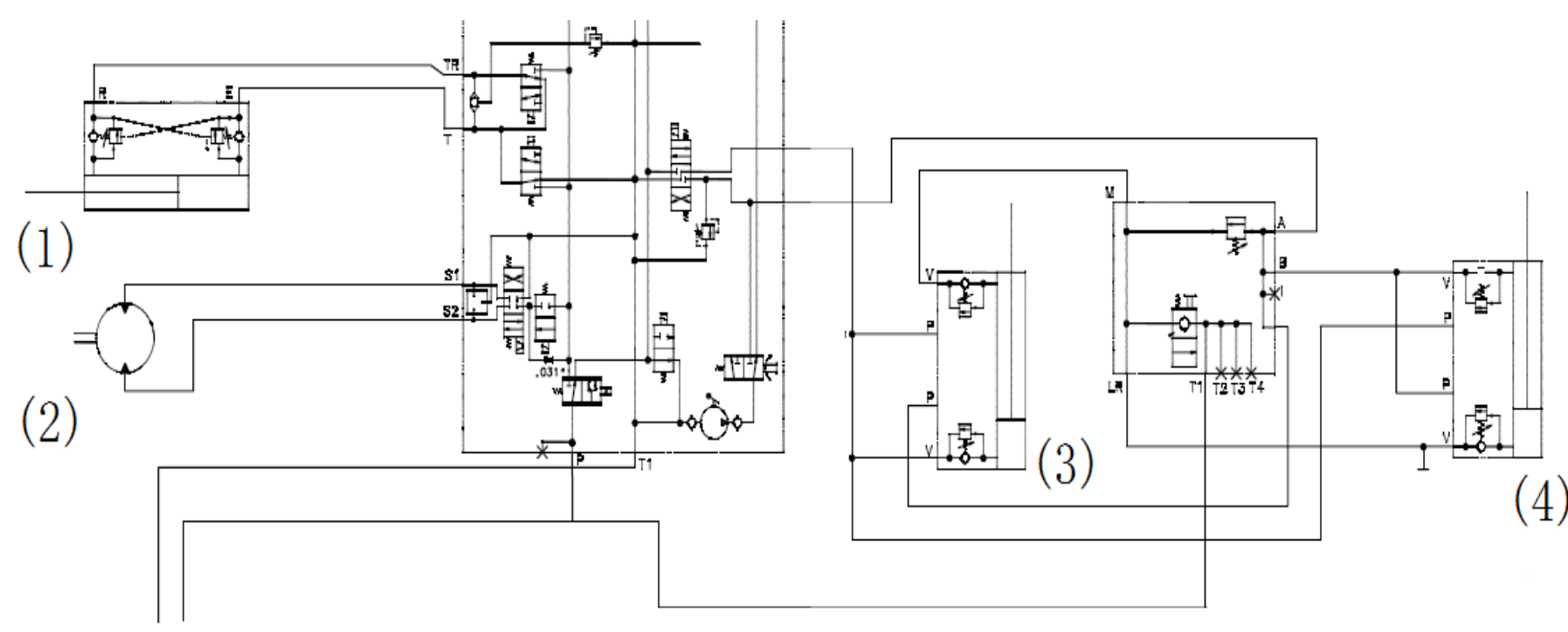

Figure 2-2 folding arm hydraulic schematic

Mechanical self-locking in the plunger of the oil cylinder installation nut. When the cylinder is increased to the required position, plunger cylinder nut rotation in the end, the cylinder body and a cylinder contact, so that the piston will is fixed to the required height the. When the need to remove the nut to screw up, so that the plunger back. This oil cylinder has a special name, called the self - locking hydraulic cylinder.

\subsection{Electrical safety system}

Power isolation is the use of isolation transformer, the isolation of the control system on the work of the isolation system to ensure that the insulation level. In the first place, the secondary of the isolated transformer is not connected with the earth, and there is no potential difference between any two wire and the earth. People are exposed to any line will not be an electric shock, so it is relatively safe.

Secondly, the isolation transformer output with the input is completely "open" isolation, so that the effective input of the transformer (the power supply network supply voltage) played a good filter (Xu Zhenbao, 2007) (Wang Fei, 2009). Thus, the pure supply voltage of the power supply device is provided.

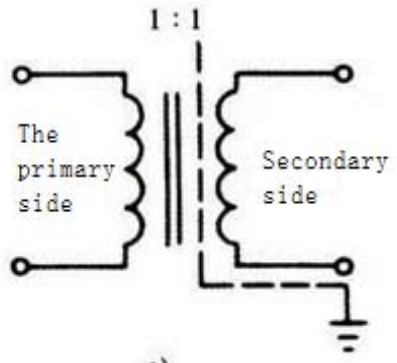

a)

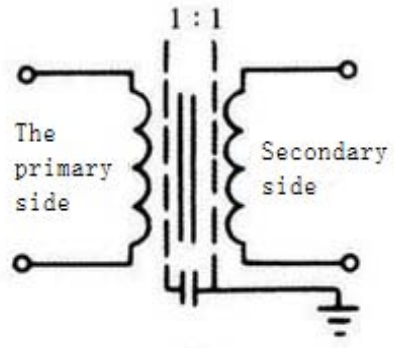

b)
In the aspect of safety warning, equipped with low power automatic alarm device, hydraulic high temperature alarm device, the mechanical arm lock alarm device and a supporting leg to reach the set torque alarm device.

\subsection{Insulation system}

Insulation system mainly includes insulation arm and insulation work. As shown in figure 2-4.

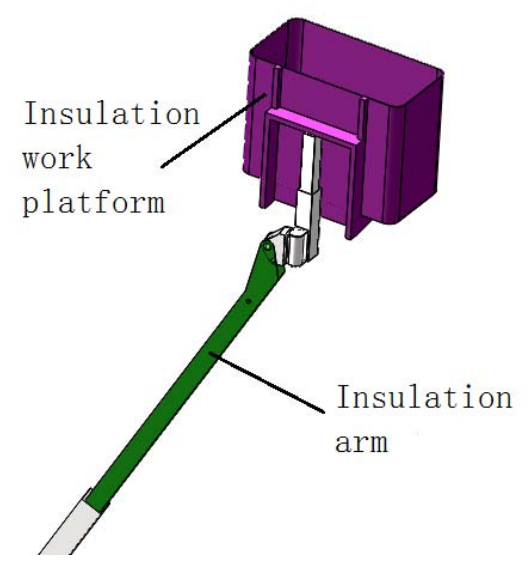

Fig. 2-4 insulation arm and insulation work

The mechanical arm of the high altitude live working vehicle is composed of two sections of a folding arm and a telescopic arm. The insulation arm is the end of the telescopic arm, must be made of insulating material. At the same time, the working platform is above $10 \mathrm{~m}$, and the strength and stiffness of the arm must be guaranteed. Insulation is the end of the work of manned platform, safety and material strength is higher. This will be through strict theoretical calculation and material testing and continuous improvement.

Fig. 2-3 isolation transformer 
Glass fiber reinforced plastics (FRP), also known as GFRP, that is, fiber reinforced plastics, glass fiber or its products for reinforced plastics, and also called glass fiber reinforced plastics. Light and hard, not conductive, stable performance, high mechanical strength, corrosion resistance ( $\mathrm{Yu}$ Xiao $\mathrm{Yu}, 2012$ ). Main parameters see table 1 .

Tab.1 Main Parameters of Insulation Material

\begin{tabular}{ll}
\hline Parameter term & parameter values \\
\hline density $/ \mathrm{kg} \cdot \mathrm{m}^{-3}$ & 1.73 \\
Tensile strength/Mpa & 290.77 \\
bending strength/Mpa & 330.06 \\
Elongation $/(\delta 5 / \%)$ & $\geq 26$ \\
Breakdown voltage of parallel layer $/ \mathrm{kV}$ & $\geq 15$ \\
Dielectric constant & $4.7 \sim 5.2$ \\
\hline
\end{tabular}

\section{SAFETY PERFORMANCE ANALYSIS}

\subsection{Electrical performance}

Power supply circuit with isolation transformer for electrical isolation and ensuring the insulation level, the transformer can also ensure insulating arm and between, between the two arms, insulation between the arm and the power generator electrical isolation and electrical equipment on the body also uses insulation protection. In addition, the anti electromagnetic interference, control system (remote control system, servo control system etc.) and between components using the shielding technology, and the use of grounding technology to increase the ability of anti electromagnetic interference (Ma Zhijun, 2004).

\section{INSULATION TEST}

\subsection{Leakage current test}

When the AC Leakage test is carried out between the insulation arm and the platform, the experimental electrode is provided with a conductive adhesive tape of $12.7 \mathrm{~mm}$, and the power frequency $\mathrm{AC}$ voltage value and leakage value are applied to the Table 2.

Tab.2 Leakage current Test

\begin{tabular}{llll}
\hline voltage $/ \mathrm{kV}$ & $\begin{array}{l}\text { distance } \\
\mathrm{L} / \mathrm{m}\end{array}$ & $\begin{array}{l}\text { voltage } \\
/ \mathrm{kV}\end{array}$ & $\begin{array}{l}\text { value } \\
/ \mathrm{uA}\end{array}$ \\
\hline 10 & 0.4 & 20 & 37.2 \\
\hline
\end{tabular}

Table 2 shows that the rated voltage is $10 \mathrm{kV}$, leakage current insulation arm length corresponding to the value below $200 \mathrm{~A}$, meets the requirements of the regulations.

\subsection{Insulation working insulation test}

The AC voltage withstand test of insulation work bucket is carried out by the continuous boost method.as shown in table 3.

Tab.3 Working Bucket Insulation Test

\begin{tabular}{cccccc}
\hline \multirow{2}{*}{$\begin{array}{c}\text { voltage } \\
\mathrm{kV}\end{array}$} & \multicolumn{4}{c}{ voltage test voltage $\mathrm{kV}$} & \multicolumn{3}{c}{ AC leak test } \\
\cline { 2 - 6 } & Distance $\mathrm{L} / \mathrm{m}$ & Acceptance test & Distance $\mathrm{L} / \mathrm{m}$ & Test voltage $/ \mathrm{kV}$ & Value $/ \mu \mathrm{A}$ \\
\hline 10 & 0.4 & 50 & 0.4 & 20 & 200 \\
\hline
\end{tabular}

Table 3 from the table, it can be known that insulation working bucket pressure to meet the requirements of the rules, the leakage current value of 200 $\mathrm{mu} \mathrm{A}$, to meet the requirements of the rules.

\subsection{Vehicle insulation test}

In addition to the bucket, insulating arm outside, to bear live working voltage of the rubber tube, hydraulic oil, cable, balancing pull rod etc. working vehicle, the vehicle should be AC Leakage test, the AC leakage value should be less than $500 \mathrm{mu}$ a. The added voltage is shown in table 4 .

Tab.4 Vehicle Insulation Test

\begin{tabular}{lll}
\hline \multirow{2}{*}{ voltage $/ \mathrm{kV}$} & \multicolumn{2}{l}{ AC leak test } \\
\cline { 2 - 3 } & voltage $/ \mathrm{kV}$ & value $/ \mathrm{uA}$ \\
\hline 10 & 20 & 35.6 \\
\hline
\end{tabular}

From table 4, the vehicle leakage current value is less than $500 \mathrm{mu} \mathrm{A}$, to meet the requirements of the procedures.

\section{CONCLUSIONS}

Through the summary and aerial electric operation vehicle related industries and product safety measures, such as ordinary aerial work truck hydraulic self-locking, electrical industry, the general safety measures electrical interlock, insulated car industry, the insulated arm and insulation work of fighting, robot industry tilt sensor and torque sensor and conversion algorithm, the application in highaltitude live line work on the car, constitute the security of the system. Hydraulic, electrical insulation, anti overturning and interlocking, safety measures complement each other. While maximizing the use of security measures, expand aerial electric operation vehicle application area and range, the better for service in modern society. 


\section{REFERENCES}

Ma Zhijun. Design of intelligent mine wind electric interlocking system based on remote network [D]. Xi'an University of Science and Technology, 2004.

Wang Fei. Research on the electro hydraulic control system of aerial work vehicle [D]. Chang'an University, 2009.

$\mathrm{Xu}$ Zhenbao. Aerial vehicle lifting arm electro-hydraulic control system of [D]. Shandong University of Science and Technology, 2007.

$\mathrm{Yu}$ Xiao Yu. Application of the hydraulic connecting rod leveling mechanism on the insulation aerial vehicle [J]. special vehicle, 2012,08:95-96.

Zhang Hua, Huo Yulan. China's development and Prospect of aerial vehicle industry $[\mathrm{J}]$. construction machinery, 2009,23:38-43. 